\title{
CUANDO LOS DERECHOS HUMANOS CHOCAN ENTRE SÍ. LAS RECOMENDACIONES DE LA ORGANIZACIÓN MUNDIAL DE LA SALUD FRENTE A LA CRISIS DEL ÉBOLA EN ÁfRICA DE 2013-2015
}

\section{PEdRo ALEJANDRo VilLarReal LizÁrRAgA ${ }^{1}$}

RESUMEN: El presente artículo pretende utilizar la perspectiva de gobernanza global para examinar la aplicación de algunos de los instrumentos jurídicos durante la crisis por el brote de ébola en África occidental, en el período de 2013-2015, que derivaron en la restricción a derechos humanos de corte individual a partir del uso de medidas de salud pública como la cuarentena y el aislamiento. El propósito es subrayar la importancia de instrumentos o documentos no-vinculantes en virtud de sus efectos jurídicos, para lo cual se recupera una parte de la creciente área de investigación en torno al concepto de gobernanza global y su relevancia para el Derecho.

Palabras clave: Epidemia de ébola, Organización Mundial de la Salud, Reglamento Sanitario Internacional, derechos individuales y colectivos, gobernanza global.

ABSTRACT: This article purports to use a global governance perspective to examine some of the legal instruments employed during the Ebola outbreak crisis in West Africa, during 2013-2015, which entailed a restriction of individual human rights through the use of public health measures such as quarantine and isolation. The purpose is to underscore the importance of non-binding instruments in light of their legal effects and, thus, part of the ever burgeoning research on global governance and its relevance for law will be invoked.

KEY Words: Ebola epidemic, World Health Organization, International Health Regulations, collective and individual rights, global governance.

1 Maestro en Derecho por la División de Estudios de Posgrado de la Facultad de Derecho de la Universidad Nacional Autónoma de México. Estudiante de doctorado en el Instituto de Investigaciones Jurídicas de dicha institución. Correo electrónico:<pedroav84@gmail.com>. 
SUMARIO: I. Introducción. II. Tensiones subyacentes entre el derecho (colectivo) a la salud y derechos individuales. III. El marco jurídico internacional de las emergencias sanitarias. IV. Principales mecanismos jurídicos internacionales empleados durante la crisis del ébola de 2014-2015. V. Más allá de lo vinculante: El enfoque de la gobernanza global y las medidas de salud pública adoptadas frente al ébola. VI. El papel de los derechos humanos a la luz de las medidas de respuesta frente al ébola. VI. Conclusiones.

\section{InTRODUCción}

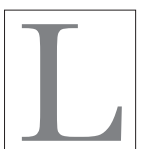

a reciente crisis del ébola en África pone de relieve que las intervenciones aisladas de unos cuantos países para contener la propagación de enfermedades no son suficientes por sí mismas para proporcionar una respuesta efectiva a este tipo de eventos. En efecto, el tono dramático de la situación se acentúa en el contexto de sistemas de salud precarios de los países africanos que han sido afectados en mayor grado, como lo son Guinea, Sierra Leona y Liberia.

Conforme al artículo 2 de la Constitución de la Organización Mundial de la Salud (OMS), dicho organismo tiene como función desempeñar el papel de "autoridad directiva y coordinadora en asuntos de sanidad internacional". Para realizar tal encomienda en el caso de emergencias sanitarias, como la actual suscitada por el ébola, la OMS tiene la facultad de emitir una serie de recomendaciones técnicas, de acuerdo con los artículo 15-18 del Reglamento Sanitario Internacional.

Si bien estas recomendaciones, como su nombre lo indica, no tienen un carácter vinculante para los Estados, no por ello carecen de relevancia para un análisis jurídico. Así, como se expone en el desarrollo de esta contribución, en ocasiones dichas recomendaciones consisten en directrices o criterios que promueven la restricción de determinados derechos individuales. Por otro lado, dicha restricción tiene lugar en el marco de la observancia de otro derecho de 
carácter colectivo, traducido en la obligación que tiene el Estado de proteger a la población frente a brotes epidémicos.

El ébola no ha adquirido la categoría formal de pandemia, ${ }^{2}$ de acuerdo con los criterios de la OMS. No obstante, la crisis de su propagación de 2013-2015 revela una serie de restricciones a los derechos humanos de corte individual, que estriban en que algunas medidas agresivas, como la cuarentena, el aislamiento e incluso el cordón sanitario, son empleadas de forma masiva para afrontar este tipo de crisis. Frente a esta situación, ¿qué papel podrían desempeñar los derechos humanos para determinar cuáles herramientas son aceptables, y cuáles no?

Puede estimarse, además, que estas medidas no se limitan al continente africano, sino que operan también como un parámetro a partir del cual se pueden extraer conclusiones para otros países en los que surjan fenómenos de magnitudes similares. De ahí la importancia de tomar en cuenta los criterios internacionales para la restricción de derechos humanos.

En esa tesitura, a continuación se procede a hacer una breve exposición de las características de los derechos humanos que entran en escena con la respuesta frente a esta crisis. Posteriormente, se hace un breve repaso de ciertos instrumentos jurídicos internacionales tanto vinculantes como otros que no lo son, como el Reglamento Sanitario Internacional o las recomendaciones técnicas de la OMS, los cuales han sido diseñados para hacerle frente a crisis de este tipo. Finalmente, se plantean algunas notas en torno a la necesidad de prestar atención a los actos de las organizaciones internacionales más allá de que sean vinculantes o no, dado que, en muchas ocasiones, las restricciones a los derechos provienen de

2 La percepción común es que esto podría obedecer al hecho de que no se le considera una enfermedad de las más virulentas. Bill Gates, "The Next EpidemicLessons from Ebola" en The New England Journal of Medicine, vol. 372, no. 15, Boston, Massachusetts Medical Society, Abril 9 de 2015, p. 1381. 
instrumentos, como las recomendaciones técnicas, que no tienen un carácter obligatorio formal.

II. Tensiones subyacientes entre el derecho (colectivo) A LA SALUd Y DERECHOS INDIVIDUALES

En el campo de las decisiones relativas al campo de la salud pública ${ }^{3}$ para combatir enfermedades contagiosas como el ébola, a menudo surgen desacuerdos o colisiones entre los intereses individuales y los colectivos. ${ }^{4}$ En este caso, las medidas consideradas como altamente restrictivas de los derechos individuales tienen ciertas salvaguardas que pretenden garantizar un uso justificado por parte de las autoridades competentes. ${ }^{5}$ La determinación de si esas medidas están

${ }^{3}$ En este artículo, se parte de una distinción entre lo referente a la salud pública, que compete a los patrones sanitarios de grupos o poblaciones - esto es, colectividades- y la medicina clínica, que corresponde a la relación concreta entre el médico y el paciente, si bien esta distinción no es siempre tajante en los hechos. Kelley Lee, "Understandings of Global Health Governance: The Contested Landscape" en Adrian Kay y Owain David Williams (eds.), Global Health Governance: Crisis, Institutions and Political Economy, Basingstoke, Editorial Palgrave-Macmillan, Gran Bretaña, 2009, p. 28; en el mismo sentido, Baltazar Pahuamba Rosas, El derecho a la protección de la salud. Su exigibilidad judicial al Estado, México, Distrito Federal, Editorial Novum, 2014, pp. 103-104.

4 Aunque el presente estudio se centra en el ébola, esto no es sólo aplicable a este padecimiento, sino también en tratándose de otras enfermedades contagiosas como la tuberculosis. Véase Luis F. Llanos-Zavalaga, José E. Velásquez-Hurtado, Patria J. García y Eduardo Gottuzzo, "Tuberculosis y salud pública: ¿Derechos individuales o derechos colectivos?" en Revista Peruana de Medicina Experimental y Salud Pública, Vol. 29, No. 2, Lima, Instituto Nacional de Salud, Junio de 2012, p. 261.

5 Lawrence O. Gostin, Public Health Law. Power, Duty, Restraint, 2a. edición revisada y expandida, Berkeley/Londres, University of California Press/The Milbank Memorial Fund, 2008. p. 12; también, Rebecca Haffajee, Wendy Parmet y Michelle Mello, "What is a Public Health "Emergency"?" en The New England Fournal of Medicine, Vol. 371, No. 11, Boston, Massachusetts Medical Society, 11 de Septiembre de 2014, p. 988. 
justificadas o no, sólo puede hacerse a través de un análisis de caso por caso, enfermedad por enfermedad.

\section{Generalidades sobre el derecho a la salud}

Se estima útil mencionar, aunque sea de paso, cuáles son los principales instrumentos jurídicos que resultan aplicables para el presente análisis del derecho a la salud. Vale la pena mencionar que se opta por una visión centrada más en los instrumentos que en los actores, aunque evidentemente los instrumentos no pueden ser entendidos en lo abstracto, sino que dependen en gran medida de su aplicación por parte de los respectivos organismos, instituciones o autoridades, que se componen por personas con diversidad de criterios y de ideologías políticas.

En primer lugar, es menester precisar que el derecho a la salud, tal como se le consagra en diversos instrumentos internacionales, tiene una dimensión colectiva y una individual. ${ }^{6}$

En cuanto a lo colectivo, esta dimensión consiste en que las personas tienen un derecho a que el Estado tome medidas para proteger la salud de la población en general. Aunque la aplicación de estos criterios se realiza en casos concretos, se entiende que el plano colectivo orienta los actos (jurídicos) de las autoridades para hacerle frente a aquellas afectaciones generalizadas contra la salud pública, a partir de lo que se asume como un "interés público". ${ }^{7}$

6 Ingrid Brena Sesma, "El derecho a la salud" en Luz María Valdés (coord.), Derechos de los mexicanos: introducción al derecho demográfico, México, Distrito Federal, Instituto de Investigaciones Jurídicas/UNAM, 2009, pp. 84-85; estas dos dimensiones también se contrastan en Héctor Faúndez Ledesma, El Sistema Interamericano de Protección de los Derechos Humanos, reimpresión de la tercera edición, San José, Instituto Interamericano de Derechos Humanos, 2009, p. 96. No son las únicas dimensiones de las que se compone el derecho a la salud, pues otros autores agregan la dimensión "positiva" y la "negativa", para referirse a qué tipo de obligación le corresponde al Estado. Véase Baltazar Pahuamba Rosas, op. cit., p. 100.

7 La noción de "interés público" se entiende en estas líneas como un espacio que es definido y delimitado, ya sea por la sociedad a través de los acuerdos previos 
En cambio, la dimensión individual corresponde a la relación que tiene cada persona en lo singular con la atención a la salud que le otorga ya sea el Estado o entes privados, en casos, por ejemplo, del acceso a los servicios de salud, o bien de la obligación de no discriminación en la atención sanitaria que brindan las instituciones de salud a las personas. ${ }^{8}$

Ciertamente, la distinción entre lo colectivo y lo individual no siempre es tan nítida. Hay ocasiones en las que una sola actividad puede afectar ambas dimensiones al mismo tiempo. Para efectos de la delimitación del tema, en estas líneas se lleva a cabo una separación conceptual entre una y otra dimensión, a la vez que se enfatiza el aspecto colectivo.

El Pacto Internacional de Derechos Económicos, Sociales y Culturales, en su artículo 12, establece un catálogo enunciativo (mas no limitativo) sobre qué es lo que incluye el derecho a la salud. Entre otros supuestos, se menciona la obligación de tomar las medidas necesarias para: "c) La prevención y el tratamiento de las enfermedades epidémicas, endémicas, profesionales y de otra índole, y la lucha contra ellas". ${ }^{9}$

expresados en normas jurídicas, o bien por las propias autoridades encargadas de gestionar su observancia. Véase Armin von Bogdandy, Hacia un nuevo derecho público. Estudios de derecho público comparado, supranacional e internacional, México, Distrito Federal, Instituto de Investigaciones Jurídicas/UNAM, 2011, pp. 105-106.

8 Estas obligaciones no necesariamente están circunscritas a la dimensión individual del derecho a la salud, pues en ocasiones hay un traslape fáctico entre lo social-colectivo y lo individual. No obstante, es importante recalcar que el carácter obligatorio de la dimensión colectiva opera más allá de que su contenido pueda individualizarse y exigirse en la vía judicial o no. Véase Baltazar Pahuamba Rosas, op. cit., p. 103.

9 De hecho, un análisis de la creación del proyecto de este artículo reveló que la redacción de dicho precepto se debió a una pretensión de expandir el contenido del derecho a la salud, tal como fue consagrado anteriormente en el preámbulo de la Constitución de la OMS. Véase Benjamin Mason Meier, "Global Health Governance and the Contentious Politics of Human Rights: Mainstreaming the 
La Observación General 14 del Comité de Derechos Económicos, Sociales y Culturales menciona en su párrafo 16 que el derecho de protección frente a epidemias:

[...] comprende la creación de un sistema de atención médica urgente en los casos de accidentes, epidemias y peligros análogos para la salud, así como la prestación de socorro en casos de desastre y de ayuda humanitaria en situaciones de emergencia. La lucha contra las enfermedades tiene que ver con los esfuerzos individuales y colectivos de los Estados para facilitar, entre otras cosas, las tecnologías pertinentes, el empleo y la mejora de la vigilancia epidemiológica y la reunión de datos desglosados, la ejecución o ampliación de programas de vacunación y otras estrategias de lucha contra las enfermedades infecciosas.

Algunos autores han considerado que, específicamente en lo que se refiere a la obligación del Estado de brindar protección frente a epidemias, ésta tiene un carácter no progresivo, sino que su observancia requiere de un cumplimiento inmediato. ${ }^{10}$ No obstante, la formulación del derecho a la salud contenida en la Observación General 14 apenas referida, no está exenta de críticas dada la dificultad que implica concretizar una dimensión colectiva de la salud en esos términos. ${ }^{11}$

Right to Health for Public Health Advancement" en Stanford Fournal of International Lare, vol. 46, no. 1, Stanford, Stanford Law School, verano de 2010, pp. 8-25.

10 Stephen P. Marks, "The emergence and scope of the human right to health" en José M. Zuniga, Stephen P. Marks y Lawrence Gostin (eds.), Advancing the Human Right to Health, Oxford University Press, Oxford (Reino Unido), 2013, p. 10. También se utiliza el término "contenido mínimo" para referirse a la parte de estos derechos que no está sujeta a un cumplimiento diferido o progresivo, en Liliana Ronconi, "Derecho a la salud: un modelo para la determinación de los contenidos mínimos y periféricos" en Salud Colectiva, vol. 8, no. 2, Buenos Aires, Centro de Estudios para la Salud, Mayo-Agosto de 2012, p. 137.

11 Benjamin Mason Meier y Larisa M. Mori, "The Highest Attainable Standard: Advancing a Collective Human Right to Public Health" en Columbia Human Rights Law Review, vol. 37, Nueva York, Columbia University School of Law, 2005, p. 101. 
2. LOS DERECHOS INDIVIDUALES EN JUEgo DURANTE UNA EMERGENCIA SANITARIA

Aunque hay una cantidad considerable de derechos que encuadran bajo la etiqueta de "individuales", pueden ubicarse a los que se mencionan en este artículo bajo el rubro de "Derechos Civiles", conforme a la formulación establecida en el Pacto Internacional de Derechos Civiles y Políticos.

Ahora bien, la consagración misma de los Derechos Civiles y Políticos se lleva a cabo en el entendido de que hay circunstancias en las que los mismos pueden ser restringidos, siempre y cuando ello obedezca al interés público, ${ }^{12}$ como lo señala la cláusula A.10 de los Principios de Siracusa sobre las Disposiciones de Limitación y Derogación del Pacto Internacional de Derechos Civiles y Políticos. Los derechos individuales consagrados por el Pacto Internacional de Derechos Civiles y Políticos que se restringen a través de las medidas para controlar la propagación del ébola son: el de libertad personal (Arts. 9 y 10) en el caso de cuarentena y aislamiento; el de libertad de movimiento o circulación (Art. 12) en lo tocante a los cordones sanitarios, restricción de viajes y toques de queda; el de reunión y de asociación (Arts. 21 y 22 del PIDCP) en cuanto al cierre de locales, plazas o edificios públicos; y, el de modalidades de respeto a la vida privada y el domicilio (Art. 17 PIDCP) respecto del cierre obligatorio de mercados generales y locales comerciales, el ingreso al domicilio sin orden judicial previa y la revisión y vigilancia epidemiológica obligatorias. ${ }^{13}$

12 A pesar de que los Principios de Siracusa mencionan "orden público" y "necesidad pública", se considera que estas figuras quedan incluidas en la idea de "interés público" que se ha presentado en párrafos precedentes.

13 Para una relación de las principales medidas de emergencia adoptadas por los países más afectados (Guinea, Liberia, Sierra Leona y Nigeria) véase la tabla detallada contenida en James G. Hodge Jr., et al , "Global Emergency Legal Responses to the 2014 Ebola Outbreak" en Journal of Law, Medicine E' Ethics, vol. 42, no. 4, Nueva York, American Society of Law, Medicine \& Ethics inc., invierno de 2014, p. 597. Esta relación entre medidas y derechos restringidos también se encuentra en Gian 
En cuanto a las tensiones entre la dimensión colectiva del derecho a la salud en el caso de protección contra enfermedades epidémicas o pandémicas, y la individual relativa a otros derechos, en concreto aquellos contemplados en el Pacto Internacional de Derechos Civiles y Políticos, es necesario llevar a cabo un análisis basado en una fundamentación principalmente técnico-científica, para evaluar si la situación justifica restringir los derechos individuales.

Dicho esto, el artículo 12, párrafo 3 del Pacto Internacional de Derechos Civiles y Políticos indica que:

[...] los derechos antes mencionados no podrán ser objeto de restricciones salvo cuando éstas se hallen previstas en la ley, sean necesarias para proteger la seguridad nacional, el orden público, la salud o la moral públicas o los derechos y libertades de terceros, y sean compatibles con los demás derechos reconocidos en el presente Pacto.

Por esta razón, la normatividad internacional prevé que hay ocasiones, como la relativa a las epidemias o pandemias, en las que los aspectos colectivos de los DESC entran inevitablemente en colisión directa con los derechos individuales provenientes del constructo de los Civiles y Políticos. ${ }^{14}$ Empero, hay que tener en cuenta de que ciertos derechos son considerados como "no derogables", lo que implica que bajo ninguna circunstancia, ni siquiera en casos de emergencias de salud pública, pueden ser motivo de restricciones. ${ }^{15}$

En este sentido, al examinar si las medidas restrictivas que se adoptan en tal o cual circunstancia son aceptables o no, se puede recurrir a lo que se ha denominado un criterio de "idoneidad" o de

Luca Burci y Riikka Koskenmäki, "Human Rights Implications of Governance Responses to Public Health Emergencies: The Case of Major Infectious Disease Outbreaks" en Andrew Clapham, Mary Robinson, Claire Mahon, y Scott Jerbi, (eds.), Realizing the Right to Health, Zürich, rüffer \& rub, 2009, p. 348.

14 La posibilidad de un "choque" entre derechos se desarrolla desde una perspectiva teórica en Martti Koskenniemi, The Politics of International Law, Oxford/ Portland, Hart Publishing, 2011, p. 142-143.

15 Lawrence O. Gostin, op. cit., p. 277. 
"adecuación técnica" de las herramientas de salud pública. ${ }^{16}$ Así, la adecuación de una medida depende, en su mayor parte, de que sea una solución atinente para el problema, esto es, que sus efectos estén orientados directamente a la obtención de la protección a la salud pública que se ha planteado; ${ }^{17}$ y, además, de que ello no implique una respuesta desproporcionada toda vez que se trata de la única disponible - esto es, que haya una ausencia de alternativas menos gravosas.$-^{18}$ No se trata de una decisión simple, sino que requiere de una evaluación pormenorizada de la situación, y es viable asumir que habrá un balance entre los derechos en juego. ${ }^{19}$

\section{El Ámbito jurídico REgional africano Relativo A} DERECHOS HUMANOS

Aunado a los instrumentos internacionales apenas invocados, resulta útil contextualizar los derechos que se han discutido en el ámbito regional africano. A simple vista, se advierte que la Carta Africana sobre los Derechos Humanos y de los Pueblos ${ }^{20}$ contiene tanto la vertiente colectiva del derecho a la salud -en el sentido que se ha

16 Véase Laura Clérico, "El derecho a la salud y el examen de proporcionalidad: Prohibición de exceso" en Laura Clérico, Martín Aldao y Liliana Ronconi, Tratado de Derecho a la Salud. Tomo II, Buenos Aires, Abeledo-Perrot, 2013.

17 Sobre este punto, y con argumentos dirigidos al caso de la tuberculosis que, no obstante, podrían ser aplicables en este contexto, véase también Edorta Cobreros Mendazona, "La voluntariedad de los tratamientos sanitarios y su excepción por riesgo para la salud pública. Especial referencia al caso de la tuberculosis en la Comunidad Autónoma Vasca”, en Revista Vasca de Administración Pública, No. 46, Oñati, Instituto Vasco de Administración Pública, Septiembre-Diciembre 1996, especialmente la p. 348.

18 Nancy E. Kass, "An Ethics Framework for Public Health" en American fournal of Public Health, vol. 91, no. 11, Nueva York, American Public Health Association, Noviembre de 2001, p. 1779.

19 Lawrence O. Gostin, op. cit., p. 12.

${ }^{20}$ Consultada en su versión en español en: <http://www.acnur.org/t3/filead$\mathrm{min} / \mathrm{scripts} /$ doc.php?file=biblioteca/pdf/1297>, [última consulta, 6 de octubre de 2015]. 
venido refiriendo y sin variaciones considerables- ${ }^{21}$ como los derechos individuales de carácter civil que están en juego en el caso de una emergencia sanitaria. Incluso, llega al punto de reafirmar el carácter indivisible de los derechos civiles y políticos, y de los derechos económicos, sociales y culturales. ${ }^{22}$

De esta manera, el artículo 16, párrafo 2, establece que todos los Estados de la región africana firmante tienen la obligación de "(tomar) las medidas necesarias para proteger la salud de su pueblo y asegurarse de que reciben asistencia médica cuando están enfermos." A partir de lo que se ha planteado en torno a esa obligación de proteger la salud, es posible interpretar el anterior numeral en conjunción con el artículo 12, inciso c) del Pacto Internacional de Derechos Económicos, Sociales y Culturales.

Por otro lado, en cuanto a los derechos individuales del rubro de los "civiles" que se encuentran directamente afectados con las medidas restrictivas en el marco de una emergencia sanitaria, el artículo 6 de la citada Carta Africana establece que "Nadie puede ser privado de su libertad más que por razones y condiciones previamente establecidas por la ley". Así, se advierte que la libertad no es un derecho absoluto, sino que es válido restringirla siempre y cuando se cumpla con un principio de legalidad. ${ }^{23}$

21 Esto también se expone en Stephen P. Marks, "The emergence and scope of the human right to health" en José M. Zuniga, Stephen P. Marks y Lawrence Gostin (eds.), Advancing the Human Right to Health, Oxford, Oxford University Press, 2013 , p. 9.

22 Sobre esta conjunción entre derechos individuales y colectivos en la Carta Africana, véase Christopher Mbazira, "Enforcing the economic, social and cultural rights in the African Charter on Human and Peoples' Rights: Twendy years of redundancy, progression and significant strides" en African Human Rights Law fournal, vol. 6, no. 2, Pretoria, Pretoria University Law Press, 2006, p. 338; igualmente, Yuria Saavedra Álvarez, "El Sistema africano de derechos humanos y de los pueblos. Prolegómenos" en Anuario Mexicano de Derecho Internacional, vol. VIII, Instituto de Investigaciones Jurídícas/UNAM, México, Distrito Federal, 2008, pp. 675-676.

23 Stephen P. Marks, "The emergence and scope of the human right to health...", op. cit., p. 14. 
Asimismo, en el marco de la Carta Africana en cuestión, tanto su artículo 11, referente al derecho a reunirse libremente, como el diverso precepto 12, que consagra la libertad de tránsito de las personas en general, admiten una restricción a esos derechos en el interés de, o para la protección de la, salud pública. De igual manera, el numeral 14 del multireferido instrumento regional africano señala que el derecho a la propiedad "podrá ser usurpado en el interés público o general de la comunidad...".

La posibilidad de limitar o restringir el ejercicio de los derechos en cita se robustece, a su vez, con el contenido del artículo 27 de la Carta en comento, que señala en su párrafo 2: "Los derechos y libertades de cada individuo se ejercerán con la debida consideración a... la seguridad colectiva... y al interés común." Además, es interesante observar cómo la Carta Africana contempla tanto derechos, como deberes para sus destinatarios. Esto introduce un esquema novedoso, para su época de redacción (1981), de salvaguarda de los derechos de las personas al considerar que éstos no sólo se respetan de forma vertical (en la relación autoridad-gobernado), sino también de forma horizontal (de individuo a individuo). ${ }^{24}$ Por ende, en el marco del derecho a la protección de la salud, cada persona tendría un deber con sus semejantes de no poner en riesgo la salud pública con sus acciones.

A simple vista, lo que se observa es que a pesar de que hay algunas diferencias entre la Carta Africana y los instrumentos internacionales generales, ${ }^{25}$ esas discrepancias no resultan ser tan sustanciales como para alterar la racionalidad de la dimensión colectiva del derecho a la protección de la salud y los múltiples derechos

24 De hecho, la Carta Africana fue el primer documento jurídico obligatorio en estipular esta visión horizontal del respeto a los derechos. Véase Yuria Saavedra Álvarez, op. cit., p. 681.

25 Por ejemplo, la Carta Africana consagra el derecho al desarrollo, mientras que los Pactos Internacionales no. Asimismo, el PIDESC contiene una exposición más detallada del derecho a la salud que la Carta Africana. Véase Christopher Mbazira, op. cit., p. 342. 
civiles individuales que entran en colisión durante una emergencia sanitaria. Por el contrario, uno y otro ámbito se complementan en la conformación de los derechos de las personas, sus alcances y sus límites, ${ }^{26}$ máxime que dichos países africanos también han suscrito tanto el Pacto Internacional de Derechos Económicos, Sociales y Culturales, como el Pacto Internacional de Derechos Civiles. Por lo tanto, las consideraciones que se plantearon en párrafos precedentes les son aplicables independientemente del contenido de la Carta Africana. ${ }^{27}$

Dicho esto, la configuración de los Derechos Civiles en ambos espacios jurídicos arrojan características similares, lo que conduce a asumir que las restricciones aceptables a su ejercicio no varían de forma dramática. Ello se robustece en tanto, de una revisión somera del texto constitucional de los países mayormente afectados, se observa que todos ellos prevén que ciertos derechos individuales pueden ser sujetos a restricciones. Esto da lugar a asumir, prima facie, que los supuestos de la Carta Africana no entran en colisión con los ordenamientos fundamentales nacionales de los países africanos en cuestión. $^{28}$

26 La Carta Africana puede ser considerada como un documento que "adapta" los instrumentos internacionales a la realidad de ese continente. Véase Mbuyi Kabunda Badi, Derechos humanos en África. Teorías y prácticas, Deusto, Universidad de Deusto, 2000, p. 290.

27 Christopher Mbazira, op. cit., p. 342.

28 La Constitución de Guinea dispone, en su artículo 6o., que "Ninguna situación de excepción o de urgencia puede justificar la violación de los derechos humanos".

Por su parte, el Artículo 15 de la Constitución de Guinea establece el derecho de toda persona a la salud, lo cual incluye un deber de los Estados de "luchar contra las epidemias".

Asimismo, la Constitución de Liberia señala que podrán limitarse la "libertad de desplazarse libremente... lo cual estará sujeto a la salvaguarda de la salud pública" (Artículo 13.a).

Por su parte, el numeral 17 de la Carta Magna de Sierra Leona estipula que "nadie podrá ser privado de su libertad excepto cuando ello sea autorizado por la ley en cualquiera de los siguientes casos... h. para el propósito de prevenir la propagación de una enfermedad infecciosa o contagiosa". 
III. EL MARCO JURÍdICO INTERNACIONAL DE LAS EMERGENCIAS SANITARIAS

El afán por controlar la propagación de las enfermedades sanitarias a través de fronteras ha sido un factor de impulso en la creación de normas internacionales orientadas a ese propósito. Desde el primer intento por crear un marco de cooperación interestatal en esta temática, que data de 1851, ${ }^{29}$ los Estados han considerado que el combate a las enfermedades contagiosas es una problemática de notable envergadura que amerita una respuesta multilateral. A continuación, se expone de forma somera cuáles son algunos de los documentos internacionales relacionados con la crisis del ébola de 2014-2015.

\section{El Reglamento Sanitario Internacional de 2005}

El principal instrumento jurídico internacional creado para el caso de la propagación transfronteriza de enfermedades como el ébola es el Reglamento Sanitario Internacional. La versión actual de este instrumento, que tiene un carácter vinculante conforme al procedimiento

Finalmente, la Constitución de Nigeria, en su artículo 35, establece que "ninguna persona podrá ser privada de su libertad salvo en los siguientes casos... (e) en el caso de personas que sufren de enfermedades infecciosas o contagiosas".

29 La primera Conferencia Sanitaria Internacional tuvo lugar en este año en París, Francia, para hacerle frente a la amenaza global que representaba el cólera en ese entonces. Véase David P. Fidler, "From International Sanitary Conventions to Global Health Security: The New International Health Regulations" en Chinese Fournal of International Law, vol. 4, no. 2, Oxford, Oxford University Press, 2005, pp. 327-328; Michael McCarthy, "A brief history of the World Health Organization" en The Lancet, vol. 360, no. 9340, Londres, Elsevier, 12 de Octubre de 2002, p. 1111; Simon Rushton, "Global Governance Capacities in Health: WHO and Infectious Diseases" en Adrian Kay y Owain David Williams, (eds.), Global Health Governance: Crisis, Institutions and Political Economy, Editorial Palgrave-Macmillan, Gran Bretaña, 2009, pp. 60-61. 
previsto en el artículo 22 de la Constitución de la OMS, ${ }^{30}$ fue signado por los Estados Miembros en 2005 y entró en vigor en 2007.

Ahora bien, el Reglamento incluye en su artículo 1 la definición de una "emergencia de salud pública de importancia internacional", consistente en que la o el Director(a) General de la OMS emite una Declaración en el sentido de que existe un "evento extraordinario que... constituye un riesgo para la salud pública de otros Estados a causa de la propagación internacional de una enfermedad y... podría exigir una repuesta internacional coordinada".

Por otro lado, el artículo 1 también define al "aislamiento" y a la "cuarentena", cuya diferencia consiste en que mientras en aquél se separa a la persona enferma u objetos contaminados, en la señalada en segundo término las restricciones se aplican a quienes no están enfermos, pero han estado en contacto con quienes sí lo están, o se sospecha de su posible contagio.

A su vez, de acuerdo con el precepto 12 del ordenamiento en cita, el/la Director(a) General de la Organización Mundial de la Salud es el funcionario competente para emitir la Declaración de la presencia de una Emergencia de Salud Pública de Importancia Internacional, cuando lo considere apropiado y después de haber consultado a un Comité de Emergencias convocado para brindarle

30 Este carácter vinculante es atípico, pues no ha seguido un procedimiento "tradicional" de firma y ratificación de tratados, sino que se trata de un instrumento jurídico diseñado en el seno de una organización internacional, como lo es la OMS. Sobre este carácter obligatorio/vinculante del Reglamento, Jennifer Prah Ruger, "Normative Foundations of Global Health Law" in The Georgetown Law Journal, vol. 96, no. 2, Washington, D.C., Georgetown University Law Center, 2008, pp. 434-435; Bradly Condon y Tapen Sinha, "The effectiveness of pandemic preparations: legal lessons from the 2009 influenza epidemic" en Florida Fournal of International Law, vol. 22, no. 1, Miami, University of Florida College of Law, Abril de 2010, pp. 4-5; David P. Fidler, "From International Sanitary Conventions to Global Health Security: The New International Health Regulations”. op. cit., p. 385; Rebecca Katz y Julie Fischer, "The Revised International Health Regulations: A Framework for Global Pandemic Response" en Global Health Governance, vol. III, no. 2, Primavera 2010, p. 2, disponible en <http://www.ghgj.org>, [última consulta, 20 de septiembre de 2015]. 
asesoría. Esta Declaración podrá ser emitida tras seguir el procedimiento estipulado en el citado artículo 12, así como en los diversos 48 y 49 del mencionado Reglamento.

En un tono similar, el artículo 15 del Reglamento Sanitario Internacional también establece que la OMS podrá emitir recomendaciones temporales o permanentes a los Estados Miembro en el marco de una Emergencia de Salud Pública de Importancia Internacional. En estas recomendaciones, podrá indicarse cuáles medidas podrán (o "habrán de") aplicar los Estados a las personas para contener la propagación internacional de una enfermedad.

Aun cuando la aplicación del Reglamento Sanitario Internacional se consideró como adecuada en el marco de la pandemia de influenza $\mathrm{A}(\mathrm{H} 1 \mathrm{~N} 1)$ de 2009-2010, con todo y las limitaciones que se evidenciaron, ${ }^{31}$ múltiples países continúan ignorando otras de las obligaciones de este instrumento, especialmente las relativas al fortalecimiento de sus sistemas de vigilancia epidemiológica. ${ }^{32}$

\section{LAS RECOMENDACIONES tÉcnicas de LA OMS}

Si bien el Reglamento Sanitario Internacional contempla una serie de obligaciones a cargo de los Estados, hay que señalar que buena parte de las funciones de la OMS enunciadas en el Artículo 2o. de su Constitución - en el que se consagra su papel de autoridad directiva y coordinadora en asuntos de sanidad internacional- se llevan a cabo a través de actos no vinculantes. De hecho, los actos formalmente vinculantes que emanan de esta organización internacional parecen tener lugar de manera excepcional. ${ }^{33}$

31 Véase el Informe del Comité de Examen acerca del funcionamiento del Reglamento Sanitario Internacional (2005) en relación con la pandemia por virus (H1N1) 2009, presentado ante la 64a. Asamblea Mundial de la Salud, disponible en: <http://apps.who.int/gb/ebwha/pdf_files/WHA64/A64_10-sp.pdf?ua=1>, [última consulta, 20 de septiembre de 2015].

32 Un reciente comentario en este sentido es el de Bill Gates, op. cit., p. 1381.

33 Esta tendencia se ha resaltado en Gian Luca Burci y Claude-Henri Vignes, World Health Organization, Kluwer Law International, La Haya, 2004, pp. 141- 
De entre estos actos, los más atinentes para el presente análisis son las recomendaciones técnicas temporales que emite la OMS durante una emergencia de salud pública de importancia internacional, las cuales, conforme a lo dispuesto por el artículo 1 del Reglamento Sanitario Internacional, no tienen carácter vinculante. En consecuencia, sus violaciones no pueden dar lugar al surgimiento de responsabilidad internacional, ${ }^{34}$ al menos no del mismo modo que los actos que emanan directamente de las fuentes de Derecho Internacional establecidas en el artículo 38 del Estatuto de la Corte Internaccional de Justicia. ${ }^{35}$

Como ya se señaló, conforme a los artículos 15 a 18 del multicitado Reglamento, cuando el/la Director(a) General de la OMS emite una Declaración de Emergencia de Salud Pública de Importancia Internacional, a la par puede expedir recomendaciones ya sea temporales o permanentes, respecto de las medidas sanitarias que se consideran como las apropiadas para hacerle frente a la emergencia.

La falta de obligatoriedad formal no implica que estas recomendaciones no son relevantes en términos jurídicos, puesto que, como

142 y 146-152; Richard G. Feachem y Jeffrey D. Sachs, (dirs.), Global Public Goods for Health. Report of Working Group 2 of the Commission on Macroeconomics and Health, Ginebra, Organización Mundial de la Salud, Agosto de 2002, p. 55.

34 Por el contrario, se estima que una inobservancia de las normas del Reglamento Sanitario Internacional sí podría conducir a responsabilidad internacional, tanto para los Estados Miembro como para la OMS, aunque hasta la fecha no se han presentado casos que invoquen dicho instrumento en el reclamo de una acción en específico. Véase Gian Luca Burci y Clemens Feinäugle, "The ILC's articles seen from a WHO perspective" en Maurizio Ragazzi (ed.), Responsibility of International Organizations. Essays in memory of Sir Ian Brownlie, La Haya Martinus Nijhoff Publishers, 2013, p. 187.

35 En este trabajo, se considera que el carácter "legal" o "vinculante" de un instrumento o documento tiene un carácter binario, en el sentido de "es/no es", aunque esto es motivo de debate en el ámbito doctrinario. Para más sobre esta discusión, véase la taxonomía que llevan a cabo Kenneth Abboth y otros, "The Concept of Legalization" en International Organization, vol. 54, no. 03, Cambridge, International Organization Foundation/Cambridge University Press, Junio de 2000 p. 410. 
se verá en líneas posteriores, el contenido o el sentido de estos actos determina el rumbo que se toma en torno a la restricción de ciertos derechos humanos en aras de proteger otros. ${ }^{36}$ Asimismo, se señala que estas circunstancias no se tratan, por cierto, de un caso aislado, sino que obedecen a un contexto en el que los actos no vinculantes, denominados soft law por algunos, ${ }^{37}$ proliferan en lo que se ha conocido como "los tiempos de la gobernanza global". ${ }^{38}$

\section{Principales mecanismos jurídicos internacionales EMPLEADOS DURANTE LA CRISIS DEL ÉBOLA DE 2014-2015}

Aunque ciertamente no fueron los únicos, a continuación se presentan los mecanismos jurídicos que se estiman como los principales para efectos de este análisis. A pesar de que hay una serie de otros instrumentos y vías informales que fungieron para dirigir el rumbo

36 En estas líneas, no se utiliza el término "soft law" para referirse a esos actos, en atención a que dicha noción puede ser confusa en cuanto al carácter jurídico que les estaría atribuyendo, dado que uno de los problemas que surgen al adoptar el término "soft law" consiste en que remite a un asunto de "grados" de vinculatoriedad, lo cual no encuentra sustento en el Derecho Internacional. Véase, p. ej. Jan Klabbers, International Law, Cambridge University Press, Cambridge, 2013, p. 38.

37 Vale la pena precisar que no se emplea el término soft law para aludir a las recomendaciones de la OMS, en la medida en que su uso da lugar a múltiples confusiones y para nada hay un acuerdo sobre sus alcances e implicaciones jurídicas, por lo que se opta por señalar simplemente que son actos no vinculantes, una cuestión constatable desde el punto de vista de la validez del Derecho Internacional Público. Sobre las críticas al concepto de soft law, véase Jan Klabbers, International Law... cit., p. 38; también, Keith Culver y Michael Giudice, "Legal System, Legality and the State: an Inter-institutional Account", en Problema. Anuario de Filosofía y Teoría del Derecho, vol. 2, Instituto de Investigaciones Jurídicas/ UNAM, México, Distrito Federal, 2008, p. 120.

38 Matthias Goldmann, "We Need to Cut Off the Head of the King: Past, Present and Future Approaches to International Soft Law" en Leiden Fournal of International Law, vol. 25, no. 2, Cambridge, Cambridge University Press, Junio de 2012, p. 366. 
de la respuesta internacional frente al ébola, este apartado se limita a aquellos provenientes de la OMS, puesto que constituye el eje rector del debate planteado al inicio.

\section{Datos generales sobre El brote de Ébola de 2O 14-2O 15}

Los datos referentes a cuándo inició exactamente el actual brote de ébola son todavía inciertos. Aunque los primeros reportes clínicos de la presencia del virus del ébola fueron emitidos por las autoridades sanitarias de Guinea en Marzo de 2014, al parecer el virus ya circulaba desde cuando menos tres meses antes. ${ }^{39}$

En el momento en que se redactan estas líneas, el conteo oficial de fallecimientos ocasionados por el ébola se encuentra en más de 28,000 casos confirmados, de los cuales más de 11,300 han sido letales, ${ }^{40}$ aunque se estima que las cifras reales son más altas. ${ }^{41}$

Ahora bien, aunque el brote ha afectado primordialmente a África occidental, hay que mencionar que el virus se encontró presente en otros países, como lo han sido Mali, Senegal, España y Estados Unidos de América. Sin embargo, en estas naciones no se ha suscitado una cadena de transmisión de persona a persona lo suficientemente sostenida como para estimar que el virus se convirtió en una

39 Se estima que la primer defunción por el virus de ébola que ocasionó la emergencia en curso ocurrió durante Diciembre de 2013, en la provincia de Guéckédou, Guinea, situada en las proximidades de la frontera con Liberia y Sierra Leona. Véase Sylvain Baize y otros, "Emergence of Zaire Ebola Virus Disease in Guinea" en The New England Fournal of Medicine, vol. 37 1, no. 15, Boston, Massachusetts Medical Society, 9 de Octubre de 2014, pp. 1418-1419 y 1421.

40 Para un reporte de la situación con información en tiempo real, véase <http://who.int/csr/disease/ebola/es/>, [última consulta, 20 de septiembre de $2015]$.

41 Es muy común lidiar con un problema de "sub-reportaje" de las cifras, en atención a la falta de un seguimiento de los casos reportados. Véase Sylvie Briand y otros, "The International Ebola Emergency" en The New England fournal of Medicine, vol. 371, no. 13, Boston, Massachusetts Medical Society, 25 de Septiembre, 2014, pp. 1180-1181. 
emergencia sanitaria también en esos países, sino que fueron casos importados aislados. ${ }^{42}$

2. Declaración de Emergencia de Salud Pública de IMPORTANCIA INTERNACIONAL

El 8 de Agosto de 2014, la Directora General de la OMS declaró que había una Emergencia de Salud Pública de Importancia Internacional, debido a la crisis de ébola que afectaba en ese entonces a Guinea, Liberia, Nigeria y Sierra Leona. ${ }^{43}$ Es apenas la tercera vez que se utiliza esta figura para hacerle frente a un problema relacionado con alguna enfermedad contagiosa. ${ }^{44}$

El lapso de tiempo transcurrido entre la notificación de la presencia del ébola en Marzo de 2014, y la fecha en que fue emitida la referida declaración, ha conducido a varias críticas respecto del deficiente papel de liderazgo por parte de la OMS. ${ }^{45}$ En este con-

42 El relato a este respecto se retoma de Justo Manuel Menéndez, Fernando Simón y José Barberán, "Enfermedad por virus ébola. Una visión global” en $R e^{-}$ vista española de quimioterapia, vol. 27, no. 4, Barcelona, J.R. Prous, 2014, p. 234.

43 Véase la "Declaración de la OMS sobre la reunión del Comité de Emergencias del Reglamento Sanitario Internacional acerca del brote de enfermedad por el virus del ébola de 2014 en África Occidental", visible en <http://who.int/ mediacentre/news/statements/2014/ebola-20140808/en/>, [última consulta, 20 de septiembre de 2015].

44 Las otras dos ocasiones fueron: el 25 de abril de 2009, día en que se declaró una Emergencia de Salud Pública de Importancia Internacional con motivo del virus de influenza $\mathrm{A}(\mathrm{H} 1 \mathrm{~N} 1)$ detectado en México, Estados Unidos y Canadá; y el 15 de mayo de 2014, día en que la OMS emitió una declaración de este tipo en virtud de la propagación del virus de la polio a lo largo de varios países pertenecientes a las regiones de Asia Central, Medio Oriente y África Central. Consultables respectivamente en: <http://who.int/mediacentre/news/statements/2009/ h1n1_20090425/es/> y <http://who.int/mediacentre/news/statements/2014/ polio-20140505/es/>, [última consulta, 20 de septiembre de 2015].

45 Por supuesto, las críticas no sólo van dirigidas a este organismo, sino a la comunidad internacional en general merced a su respuesta diferida. Véase Lawrence Gostin y Eric Friedman, "Ebola: a crisis in global health leadership" en The Lancet, 
texto, hay que precisar el hecho de que el artículo 9 del Reglamento Sanitario Internacional prevé la posibilidad de recibir "informes procedentes de fuentes distintas", refiriéndose a actores no estatales, ${ }^{46}$ si existen posibles eventos que impliquen un riesgo para la salud pública internacional. Luego, el aviso por parte de Médicos Sin Fronteras, encuadra dentro de los supuestos que la OMS estaba obligada a tomar en consideración, tal como lo prevén los numerales 9 a 12 del referido Reglamento.

Por otro lado, las obligaciones jurídicas inmediatas para los Estados que resultan de este tipo de declaraciones consisten, conforme al Reglamento Sanitario Internacional, en un incremento en la vigilancia epidemiológica y el reportar con celeridad cualquier posible caso de ébola que se detecte en su territorio. ${ }^{47}$

Vale la pena precisar que la declaración de una Emergencia de Salud Pública de Importancia Internacional puede surgir por motivos que no se limitan al brote de una enfermedad contagiosa, sino también a eventos de distinta índole, pues en el Anexo 2 del Reglamento Sanitario Internacional, se establece un diagrama denominado "Instrumento de Decisión para la Evaluación y Notificación de Eventos que pueden constituir una Emergencia de Salud Pública

vol. 384, no. 9951, Londres, Elsevier, 11 de Octubre de 2014, pp. 1322-1324; asimismo, vale la pena consultar el detallado informe de Médicos Sin Fronteras, quienes estuvieron en contacto directo con la población durante el brote inicial de ébola, titulado Pushed to the Limit and Beyond. A year into the largest ever Ebola outbreak, disponible en <http://www.msf.org/article/ebola-pushed-limit-and-beyond>, [última consulta, 20 de septiembre de 2015].

46 Este aspecto del Reglamento Sanitario Internacional de 2005 es desarrollado de forma más pormenorizada en David P. Fidler, "From International Sanitary Conventions to Global Health Security: The New International Health Regulations", op. cit., pp. 374-375.

47 Ibidem, p. 385; Bradly Condon y Tapen Sinha, "The effectiveness of pandemic preparations: legal lessons from the 2009 influenza epidemic"... cit., pp. 4-5; Rebecca Katz, "Use of Revised International Health Regulations during Influenza A(H1N1) Epidemic, 2009" en Emerging Infectious Diseases, vol. 15, no. 8, Atlanta, Centers for Disease Control and Prevention, Agosto de 2009, pp. 1166-1168. 
de Importancia Internacional". El hecho de que se distinga entre "enfermedades" y "eventos distintos", podría indicar la inclusión de catástrofes de otro tipo, ya sean naturales o producidas por el hombre. ${ }^{48}$ Empero, hasta la fecha esta característica permanece en el plano hipotético, dado que, como se menciona con antelación, esta figura sólo ha sido utilizada en casos de brotes de enfermedades contagiosas.

3. Las recomendaciones temporales de la OMS en el CASO DEL ÉBOLA

Aunque la magnitud de la crisis del ébola de 2014 condujo a reacciones no sólo por parte de la OMS, sino de muchos otros organismos internacionales, ${ }^{49}$ estas líneas se limitan a un análisis de las recomendaciones emitidas por la citada organización internacional.

48 Los desastres nucleares, como el ocurrido en Fukushima, Japón, en 2011 , si bien generan efectos perniciosos en la salud, son competencia en primer término del Organismo Internacional de Energía Atómica. Así los principales instrumentos normativos aplicables son la Convención sobre la pronta notificación de un accidente nuclear, así como la Convención sobre Asistencia en caso de Accidente Nuclear o Emergencia Radiológica, aunque hay una participación conjunta de la Organización Mundial de la Salud en caso de un evento de este tipo, según el artículo 6 del Reglamento Sanitario Internacional. Se ha señalado que dicho Reglamento es también aplicable a ese fenómeno, según se aprecia en The WHO Quarterly Bulletin on IHR Implementation, no. 14, Organización Mundial de la Salud, 8 de Abril de 2011, visible en <http://www.who.int/ihr/ihrnews/IHR_news_No_14.pdf>, [consultado el 20 de septiembre de 2015].

49 Cabe destacar las resoluciones 2176 y 2177 (2014), ambas del Consejo de Seguridad de las Naciones Unidas, en la que reitera la necesidad de actuar bajo el marco de los protocolos y recomendaciones de la OMS, con el propósito de atender el brote de ébola en aras de mantener la paz y la seguridad internacionales. Disponibles, respectivamente, en: <http://www.refworld.org/cgi-bin/texis/vtx/ rwmain/opendocpdf.pdf? ?reldoc $=$ y\&docid $=546 f 0 d d 24>$ y $<$ https: $/ /$ www.ifrc. org/docs/IDRL/Consejo\%20de\%20Seguridad\%202177.pdf>, [última consulta, 20 de septiembre de 2015]. 
En este sentido, derivado de lo establecido en el numeral $18.1 \mathrm{del}$ Reglamento Sanitario Internacional, la OMS puede aconsejar, entre otras medidas, el uso de la cuarentena y el aislamiento, cuando ello sea pertinente. La Directora General así lo hizo, en el momento en que declaró la presencia de una Emergencia de Salud Pública de Importancia Internacional, puesto que las recomendaciones incluían utilizar el aislamiento de casos confirmados y cuarentena de las personas que hubiesen estado en contacto con un enfermo de ébola "si se consideran necesarias". ${ }^{50}$

Como se señaló con anterioridad, la inobservancia de estas recomendaciones no pueden dar lugar a responsabilidad internacional. Sin embargo, no puede pasarse por alto el que tienen una influencia considerable en los Estados, ya que son adoptadas como pautas para la acción por los gobiernos, dado que se asumen como el acto de una organización con funciones y capacidades técnico-científicas, como lo es la OMS. ${ }^{51}$

50 En el caso particular, las cuarentenas pueden implementarse de diversas maneras, en tanto las recomendaciones no señalan explícitamente un confinamiento de las personas, sino sólo una restricción parcial del movimiento nacional y absoluta en cuanto al transporte internacional de las personas que entraron contacto con enfermos de ébola. "Declaración de la OMS sobre la reunión del Comité de Emergencias del Reglamento Sanitario Internacional acerca del brote de enfermedad por el virus del ébola de 2014 en África Occidental", op. cit. Estas indicaciones también se puede consultar en el documento Hoja de ruta para la respuesta al virus de ébola, Organización Mundial de la Salud, Ginebra, 28 de Agosto de 2014, p. 8, visible en: <http://apps.who.int/iris/bitstream/10665/135590/1/ WHO_EVD_Roadmap_14.1_spa.pdf?ua=1\&ua=1>, [última consulta, 20 de septiembre de 2015].

51 Este razonamiento también estuvo presente durante el brote de SARS de 2003, durante el cual la OMS asumió un papel de liderazgo a pesar de que en aquel entonces carecía de las facultades legales otorgadas por el Reglamento Sanitario Internacional de 2005. Véase Daniel Esty, "Good Governance at the Supranational Scale: Globalizing Administrative Law", en The Tale Law Fournal, vol. 115, no. 7, New Haven, Yale Law School, Estados Unidos, Mayo de 2006, p. 1551. 
En el mismo orden de ideas, puede asumirse que las recomendaciones técnicas gozan de influencia ${ }^{52}$ entre los Estados porque se estima que reflejan el estado del conocimiento científico en el momento de su emisión. Se dice esto, puesto que los artículos 17, 47 y 48 del RSI, estipulan que las recomendaciones las emitirá el (la) Director(a) General, tras llevar a cabo una consulta a un Comité de Emergencias compuesto por expertos en la materia, seleccionados a partir de una Lista (Roster) previamente definida. ${ }^{53}$

Aunado a lo anterior, conforme al artículo 43 del RSI, los países pueden adoptar medidas adicionales, siempre y cuando éstas no sean más restrictivas o invasivas que otras opciones razonablemente disponibles, si es que existen. Por lo tanto, el catálogo enumerado en las recomendaciones de la OMS no necesariamente es limitativo, sino que permite recurrir a otras que no han sido incluidas de forma explícita.

4. LA IMPORTANCIA DE LOS ACTOS NO VINCULANTES FRENTE A LA TENSIÓN DE DERECHOS HUMANOS EN EL MARCO DEL ÉBOLA

Las medidas de salud pública como la cuarentena, el aislamiento y el cordón sanitario, que han sido adoptadas en el contexto de la emergencia sanitaria ocasionada por el ébola de 2014, son altamente restrictivas de derechos. Asimismo, su uso se encuentra promovi-

52 Aunque en este trabajo no se abunda más en este debate, esta "influencia" puede traducirse a una discusión más detallada sobre su legitimidad de tipo "técnica" o "basada en expertos", como se le ha denominado por algunos, como por ejemplo, Ingo Venzke, "International Bureaucracies from a Political Science Perspective - Agency, Authority and International Institutional Law" en Armin von Bogdandy y otros (eds.), op. cit., pp. 83-85.

53 La relación de los integrantes y asesores del Comité de Emergencias en el caso del ébola, puede ser consultada en <http://www.who.int/ihr/procedures/ emerg_comm_members_20140806/en/>, [última consulta, 20 de septiembre de $2015]$. 
do de forma explícita en las recomendaciones técnicas de la OMS, efectuadas a la par de la Declaración de 8 de Agosto de 2014 sobre la presencia de una Emergencia de Salud Pública de Importancia Internacional por la propagación del ébola a lo largo de países de África Occidental. La trascendencia de las recomendaciones, se reitera, estriba en que los criterios de la OMS fungen, entre otras cosas, como pauta para determinar cuándo hay una justificación científica para la imposición de medidas como la cuarentena, el aislamiento, o incluso las de carácter más draconiano como el cordón sanitario. ${ }^{54}$

Entonces, los debates sobre la gestión de la respuesta frente al ébola han versado sobre la falta de capacidades de infraestructura encaminada a aplicar las medidas restrictivas, y no tanto sobre la justificación de emplearlas. Esto es, se asume prima facie que se está ante restricciones aceptables a los derechos individuales, toda vez que la propagación acelerada del virus y las múltiples carencias de los sistemas de salud de los países africanos no dan lugar a alternativas.

En el presente caso es harto difícil encontrar un argumento viable en contra de la justificación de las multicitadas medidas. A pesar de que está lejos de ser un balance ideal entre las dimensiones colectiva e individual de los derechos, lo cierto es que las decisiones tienen que adaptarse al entorno social africano, donde han imperado los conflictos armados y el olvido sistemático, por lo que las herramientas disponibles distan sobremanera de ser las ideales. ${ }^{55}$ Esto

54 Para relatos sobre la manera en que fue implementado el cordón sanitario en la zona fronteriza de Guinea, Liberia y Sierra Leona, véase "Un millón de personas, aisladas con cercos sanitarios por el ébola" en La fornada, 16 de Agosto de 2014, visible en: <http://www.jornada.unam.mx/2014/08/16/ sociedad/029n1soc>. También, Donald G. Mcneil Jr., "Using a Tactic Unseen in a Century, Countries Cordon Off Ebola-Racked Areas" en The New York Times, 12 de Agosto de 2014, disponible en: <http://www.nytimes.com/2014/08/13/ science/using-a-tactic-unseen-in-a-century-countries-cordon-off-ebola-rackedareas.html?_r=1>, [última consulta, 20 de septiembre de 2015].

55 Se recalca esta situación en Bill Gates, "The Next Epidemic-Lessons from Ebola", op. cit., 1382. 
último se ilustra todavía más porque, a pesar de que hay recientes investigaciones relativas a vacunas con potencial para cambiar el escenario, éstas no se encontraban disponibles al inicio "formal" de la emergencia. ${ }^{56}$ Por lo tanto, fue latente durante esta crisis la persistente ausencia de una alternativa menos restrictiva que las medidas de salud pública adoptadas hasta ahora en el marco del ébola, si bien esto no justifica del todo su uso indiscriminado como si se tratase de un "cheque en blanco". ${ }^{57}$

Cabe señalar que ha habido países que implementaron una restricción total a los vuelos provenientes de las regiones afectadas por el virus. ${ }^{58}$ Independientemente de que la precaución esté fundamentada o no, lo cierto es que estas medidas pueden considerarse como excesivas. Se dice lo anterior, en tanto, por un lado, no hay ninguna justificación científica en el sentido de que esto detendrá la propagación y, por el otro, se incrementa el riesgo de empeorar la situación, puesto que contribuyen aun más al deterioro de la economía de los países directamente afectados. ${ }^{59}$

56 Véase el reciente éxito de los ensayos clínicos realizados respecto de una posible vacuna para el ébola en <http://www.who.int/mediacentre/news/releases/2015/effective-ebola-vaccine/en/>, [última consulta, 20 de septiembre de $2015]$.

57 Medidas similares fueron desplegadas en China durante el brote del Síndrome Respiratorio Agudo Severo (SARS, por sus siglas en inglés) de 2003, y aunque eventualmente se logró superar esta crisis, se cree que hubo un uso excesivo de las restricciones a los derechos individuales debido a su empleo generalizado. Véase Matthew K. Wynia, "Ethics and Public Health Emergencies: Restrictions on Liberty" en The American Fournal of Bioethics, Vol. 7, No. 2, Taylor \& Francis Group Inc., Cambridge, Febrero de 2007, pp. 2-3.

58 Aunque no se enumeran los países que incurrieron en este proceder, este hallazgo fue descrito en la 5a. reunión del Comité de Emergencias de la OMS, celebrada el 10 de Abril de 2015, visible en <http://www.who.int/mediacentre/news/ statements/2015/ihr-ec-ebola/en/>, [última consulta, 20 de septiembre de 2015].

59 De entre las distintas recomendaciones técnicas emitidas por la OMS, se encuentra la de no implementar restricciones generales al transporte aéreo. Véase Declaración de la OMS sobre la reunión del Comité de Emergencias del Reglamento Sanitario Internacional acerca del brote de enfermedad por el virus del ébola de 2014 en África Occidental, op. cit. 
v. Más allá de lo vinculante: El enfoque de la GOBERNANZA GLOBAL $Y$ LAS MEDIDAS DE SALUd PÚBLICA ADOPTADAS FRENTE AL ÉBOLA

Aunque sea de manera breve y superficial, se estima necesario señalar en qué sentido se emplea el término gobernanza global en este trabajo, y cuál es su relevancia para el análisis de lo acontecido en el ámbito del derecho internacional durante la crisis del ébola. Esto tiene como objetivo el impedir confusiones conceptuales en cuanto sea posible, ya que la polisemia de la que es objeto el referido término puede dar lugar a una multitud de temas, conexos pero no idénticos entre sí.

1. Variante de gobernanza global adoptada en estas LÍNEAS

La noción o concepto de gobernanza global es polisémica, y ha sido objeto de innumerables aproximaciones doctrinales. ${ }^{60}$ Se considera útil precisar cuál de todas las acepciones es la que se emplea en estas líneas.

Por un lado, gobernanza global alude a los procesos de transformación que ha experimentado el Estado a raíz de la fase actual de proceso de globalización, particularmente a través de una diversificación en cómo se toman las decisiones respecto de temas considerados de interés público, de ahí que ambos conceptos hayan evolucio-

60 Para un acercamiento a la manera en que ha tenido lugar esta proliferación, véase David Levi-Faur, "From Big Government" to "Big Governance?" en David Levi-Faur, (ed.), The Oxford Handbook of Governance, Oxford University Press, Nueva York, 2012, p. 5 y ss.; asimismo, James N. Rosenau, "Governance in the Twenty-first Century" en Global Governance, Vol. 1, No. 1, Lynne Rienner Publishers, Boulder, Invierno de 1995, p. 13 y ss.; de igual manera, véase José María Serna de la Garza, Impacto e Implicaciones Constitucionales de la Globalización en el Sistema furídico Mexicano, Instituto de Investigaciones Jurídicas/UNAM, México, Distrito Federal, 2012, pp. 69-71. 
nado más o menos de forma paralela. ${ }^{61}$ Tal afirmación cobra fuerza en el ámbito internacional, también por el hecho de que no hay un gobierno central encargado de cumplir con todas las funciones propias de un Estado nacional. ${ }^{62}$

Entonces, una de las vertientes de la idea de gobernanza global se enfoca en el hecho de que la comunidad internacional opera a través de una multitud de relaciones no-jerárquicas, ${ }^{63}$ donde también se asume que los Estados ya no tienen el papel único de toma de decisiones a nivel internacional -si es que alguna vez lo tuvieron de forma categórica-, sino que hay una participación cada vez mayor de actores no estatales en los procesos de creación de normas y reglas, así como para la vigilancia del cumplimiento de las mismas. ${ }^{64}$ A pesar de que

61 Jim Whitman, The Fundamentals of Global Governance, Palgrave Macmillan, Basingstoke, 2009, pp. 3-4; Martin Hewson y Timothy J. Sinclair, "The Emergence of Global Governance Theory" en Martin Hewson y Timothy J. Sinclair, (eds.), Approaches to Global Governance Theory, State University of New York Press, Nueva York, 1999, p. 16.

62 Empero, hay voces que sí contemplan la posibilidad del surgimiento de un Estado mundial propiamente dicho, como por ejemplo Alexander Wendt, "Why a World State is Inevitable" en Luis Cabrera (ed.), Global Governance, Global Government. Institutional Visions for an Evolving World System, State University of New York Press, Nueva York, 2011, pp. 55-56. Sin embargo, tal propuesta es altamente polémica y lejos de ser universalmente aceptada en la literatura, como se observa en la opinión contraria de Anne-Marie Slaughter, A New World Order, Princeton University Press, Princeton, 2004, especialmente pp. 262-263 y 270.

63 Sobre la idea de "horizontalidad", véase Benedict Kingsbury, Nico Krisch y Richard B. Stewart, "El surgimiento del Derecho Administrativo Global" en El nuevo Derecho Administrativo Global en América Latina. Desafios para las Inversiones Extranjeras, la Regulación Nacional y el Financiamiento para el Desarrollo, Ediciones RAP, S.A., Buenos Aires, 2009, p. 75; David Levi-Faur, "From "Big Government" to "Big Governance", op. cit., p. 7.

64 Tanja Brühl y Volker Rittberger, "From International to Global Governance: Actors, collective decision-making and the United Nations in the world of the twenty-first century", en Volker Rittberger (ed.), Global governance and the United Nations System, Tokyo, United Nations University Press, 2001, p. 2; Tanja E. Aalberts, "Patterns of Global Governmentality and Sovereignty" en Stefano Guzzini y Iver B. Neumann (eds.), The diffusion of power in global governance. International Political Economy Meets Foucault, Houndmills, Palgrave-Macmillan, 2012, p. 234; para ejemplos de cómo dicha idea también encuentra eco en el ámbito de 
esta variante también resultaría pertinente para el estudio de caso del ébola, toda vez que hubo una presencia notable en la respuesta a la crisis por parte de organismos no gubernamentales como Médicos Sin Fronteras, por el momento no se profundiza más en este rumbo.

Ahora bien, otra de las aportaciones del concepto de gobernanza es su énfasis en cómo los asuntos públicos son gestionados a partir de actos considerados como "informales", cuyos efectos o consecuencias en ocasiones superan a los de actos más "formales". ${ }^{65}$ Más allá de los actores que emitan unos u otros, esta afirmación tiene una relevancia directa para el Derecho si se toma en cuenta que las normas o reglas jurídicas conllevan un grado máximo de formalidad, ${ }^{66}$ mientras que otros actos, como lo serían las recomendaciones de la OMS, poseen un nivel menor. ${ }^{67}$

Por otra parte, la conformación del elemento global del término en cuestión se apoya en una perspectiva multi-nivel, según la cual hay una simultaneidad en las decisiones adoptadas en los ámbitos local/nacional, regional e internacional general. ${ }^{68}$ Así se desprende, por ejemplo, del hecho de que las medidas de cuarentena y aisla-

la Salud Pública, véase Matthew Hoisington, "A Special Role for the World Health Organization in the Creation of a Living, Breathing Global Health Governance Constitution" en Global Health Governance, Vol. VI, No. 2, Verano de 2013, p. 2, disponible en: <http://ghgj.org>, [última consulta, 20 de septiembre de 2015].

65 Henk Overbeek, "Global Governance: From Radical Transformation to Neo-Liberal Management” en International Studies Review, Vol. 12, No. 4, Malden, International Studies Association/Blackwell Publishers, Diciembre de 2010, p. 700.

${ }^{66}$ James Rosenau, "Governance in the Twenty-first Century"... op. cit., p. 29; esto se enfatiza también en Armin von Bogdandy, Matthias Goldmann y Philipp Dann, "Developing the Publicness of Public International Law...", op. cit., p. 7.

67 Esto da lugar también a un debate polémico sobre la posibilidad de concebir una "normatividad relativa" en el ámbito internacional, que obedezca a criterios de grados de vinculatoriedad, lo que genera no pocas críticas. Matthias Goldmann, "We Need to Cut Off the Head of the King: Past, Present and Future Approaches to International Soft Law" en Leiden Fournal of International Law, vol. 25, no. 2, Cambridge, Cambridge University Press, Junio de 2012, pp. 341-342.

68 Armin von Bogdandy, Hacia un nuevo derecho público. Estudios de Derecho Público comparado, supranacional e internacional, op. cit., p. 99; Michael Zürn, "Global 
miento adoptadas se encuentran justificadas desde el punto de vista jurídico tanto en el marco del RSI (espacio internacional general), como en el de la Carta Africana (espacio regional) y las Constituciones de los países principalmente afectados (espacio local/nacional).

Dicho esto, la idea de gobernanza global a la que se limita el presente análisis es la que se centra en las decisiones informales o no-vinculantes -entendido como una cuestión de grado, como se precisa en párrafos anteriores- que presentan una dimensión multi-nivel en cuanto al ámbito de donde provienen, sus efectos y los fundamentos jurídicos intrínsecos.

2. El uso del enfoque de gobernanza global en el caso DE LAS MEDIDAS DE SALUd PÚBLICA DE RESPUESTA AL ÉBOLA

Las decisiones de la OMS que derivan en la emisión de recomendaciones técnicas en tal o cual sentido, y sus efectos jurídicos a pesar de su no-vinculatoriedad, pueden abordarse a partir de la visión de gobernanza global que fue presentada en el apartado previo.

Conforme a la perspectiva que se ha planteado a lo largo del artículo, la aceptabilidad de tal o cual medida sólo puede determinarse en un caso por caso, enfermedad por enfermedad. No es posible, por el momento, plantear en términos generales una afirmación en el sentido de que las medidas restrictivas como la cuarentena o el aislamiento están justificadas para cualquier escenario de propagación de enfermedades, pues en otras ocasiones se ha afirmado que no son útiles, como durante la pandemia de influenza $\mathrm{A}(\mathrm{H} 1 \mathrm{~N} 1)$ 2009-2010, en virtud del alto grado de contagio de este virus y las dificultades que implica rastrear y aislar a los contactos. ${ }^{69}$ Más bien,

Governance as Multi-level Governance" en David Levi-Faur, The Oxford Handbook of Governance, op. cit., p. 731.

69 Véase las directrices de la OMS a este respecto, Preparación y respuesta ante una pandemia de influenza, Organización Mundial de la Salud, Ginebra, 2009, p. 69; también, Gregory P. Campbell, "The Global H1N1 Pandemic, Quarantine Law, and the Due Process Conflict" en San Diego International Law fournal, vol. 
la decisión dependerá de las características epidemiológicas de la enfermedad de que se trate, lo que a su vez justifica el que se haya elegido al ébola en lo particular.

Así, a través de las recomendaciones técnicas, la OMS proporcionó un fundamento jurídico para las medidas agresivas adoptadas por los gobiernos de Guinea, Sierra Leona, Liberia y Nigeria. Los acontecimientos permiten suponer que la adopción de medidas como la cuarentena y el aislamiento no podían ser optativas, sino que es necesaria su imposición obligatoria. Ciertamente, esto es más fácil de pregonar que de realizar, sobre todo si se trata de países con una muy limitada capacidad de respuesta frente a emergencias sanitarias.

Ahora bien, aunque las medidas adoptadas para hacerle frente a la crisis fueron altamente restrictivas, lo cierto es que parecen haber cumplido su objetivo de mitigar la propagación del virus. Ello se ilustra por lo acontecido en el caso índice de ébola en Nigeria, Patrick Sawyer, ${ }^{70}$ país en el que se logró reducir a cero el núme-

12, no. 2, San Diego, University of San Diego School of Law, 2011, p. 510; en el mismo sentido, Hodge Jr., James G., "Global Legal Triage in Response to the 2009 H1N1 Outbreak" en Minnesota Fournal of Law, Science E Technology, vol. 11, no. 2, Mineápolis, University of Minnesota Law School, primavera de 2010, p. 607.

70 Se estima que Patrick Sawyer fue quien introdujo el virus en ese país, proveniente de Liberia. La pronta acción de las autoridades al aislarlo logró impedir la escalada hacia una crisis como la de los países más golpeados, a pesar de que para hacerlo tuvieron que detener al paciente cuando intentó huir del hospital. Véase las notas en los periódicos El Financiero y El Universal, disponibles respectivamente en: <http://www.elfinanciero.com.mx/mundo/nigeria-confir ma-el-segundo-caso-de-ebola.html> y <http://www.eluniversal.com.mx/el -mundo/2014/suman-16-casos-de-ebola-en-nigeria-1034620.html>, [última consulta, 20 de septiembre de 2015]. También consúltese, sobre esta historia, Sarathi Kalra y otros, "The Emergence of Ebola as a Global Health Security Threat: From "Lessons Learned" to Coordinated Multilateral Containment Efforts" en Fournal of Global Infectious Diseases, vol. 6, no. 4, Tampa, International Infectologists Network, Octubre-Diciembre 2014, p. 171; por último, el relato sobre la reacción del personal médico que atendió a Patrick Sawyer puede consultarse en <http://www.bbc.com/news/world-africa-30199004>, [última consulta, 20 de septiembre de 2015]. 
ro de contagios a partir de la aplicación del aislamiento. Empero, para nada puede servir esto a manera de justificación de un uso indiscriminado y excesivo de esas medidas, pues este criterio podría resultar contraproducente. ${ }^{71}$ Aunque no siempre es fácil diagnosticar de forma certera cuándo se justifica el uso de estas medidas y cuándo no, especialmente en un panorama complicado desde el punto de vista socioeconómico como lo es África occidental, vale la pena hacer ese esfuerzo en aras de impedir un abuso sistemático a los derechos humanos.

Precisamente por esta razón, hay que insistir en la atención que merecen los actos internacionales no vinculantes desde una perspectiva jurídica. El uso de conceptos como el de gobernanza global ha contribuido, entre otras cosas, al entendimiento de que los efectos de facto vinculantes no sólo provienen de los actos formalmente obligatorios. ${ }^{72}$ Tal es el caso de las recomendaciones técnicas de la OMS, que son las que en mayor grado definen la aceptabilidad de una restricción de derechos durante un brote epidémico. ${ }^{73}$

A grandes rasgos, puede afirmarse que estas recomendaciones tienen un efecto mayor al que indicaría su denominación, ya que la posibilidad de ignorarlas en algunas situaciones podría ser más ilusión que realidad. ${ }^{74} \mathrm{Su}$ peso o influencia quizá proviene de una

71 James G. Hodge Jr. y otros, "Global Emergency Legal Responses to the 2014 Ebola Outbreak", op. cit., p. 599.

72 Armin von Bogdandy, Matthias Goldmann y Philipp Dann, "Developing the Publicness of Public International Law: Towards a Legal Framework for Global Governance Activities" en Armin von Bogdandy y otros (eds.), op. cit., p. 11; Henk Overbeek, "Global Governance: From Radical Transformation to NeoLiberal Management”, op. cit., p. 700.

73 Incluso, los Principios de Siracusa, mencionados en una parte precedente, remiten directamente a la Organización Mundial de la Salud, para establecer cuándo es apropiado dictaminar límites a los derechos individuales en aras de salvaguardar la salud pública.

74 Sobre este peso de algunos instrumentos no vinculantes, véase Armin von Bogdandy, Matthias Goldmann y Philipp Dann, "Developing the Publicness of Public International Law: Towards a Legal Framework for Global Governance Activities", op. cit., p. 10; Kenneth W. Abbott y Duncan Snidal, "Hard and Soft 
multitud de factores: que el acto proviene de una organización internacional que goza de autoridad en términos técnico-científicos ${ }^{75}$ que por su presencia internacional, las conclusiones a las que llega la organización pueden ser más acertadas que las que formule cada país en lo individual ${ }^{76}$ o que, de plano, los beneficios de ajustarse a ellos superan por mucho a las desventajas de desatenderlos. ${ }^{77}$

De ahí, que más allá de su carácter vinculante o no, es necesario incluir a las recomendaciones de la OMS en cualquier análisis jurídico que verse sobre la justificación de las medidas de cuarentena y aislamiento, a sabiendas de que continúa pendiente el debate sobre cuál es su naturaleza legal.

\section{vi. El papel de los derechos humanos a la luz de las MEDIDAS DE RESPUESTA FRENTE AL ÉBOLA}

En el contexto de sistemas de salud altamente precarios, como los de los países africanos principalmente afectados, ${ }^{78}$ así como las

Law in International Governance" en International Organization, vol. 54, no. 3, Cambridge, International Organization Foundation/Cambridge University Press, Junio de 2000, p. 456.

75 Ingo Venzke, "International Bureaucracies from a Political Science Perspective-Agency, Authority and International Institutional Law" Armin von Bogdandy et al., (eds.), op. cit., pp. 83-85.

76 Armin von Bogdandy y Matthias Goldmann, "The Exercise of International Public Authority through National Policy Assessment. The OECD’s PISA Policy as a Paradigm for a New International Standard Instrument" en International Organizations Law Review, vol. 5, no. 2, Leiden/Boston, Martinus Nijhoff Publishers, 2008, p. 260; Harvey Fineberg, "Pandemic Preparedness and Response. Lessons from the H1N1 Influenza of 2009", en The New England Fournal of Medicine, vol. 370, no. 14, Boston, Massachusetts Medical Society, Abril de 2014, p. 1341

77 Armin von Bogdandy, Matthias Goldmann y Philipp Dann, "Developing the Publicness of Public International Law: Towards a Legal Framework for Global Governance Activities" en Armin von Bogdandy y otros (eds.), The Exercise of Public Authority by International Institutions. Advancing International Institutional Law, op. cit., p. 12.

78 De hecho, los países que han sido más golpeados por el ébola tienen niveles de desarrollo en infraestructura sanitaria, que se encuentran entre los más bajos del mundo. Véase Lawrence O. Gostin, "Ebola: towards an International Health 
limitaciones de los avances médicos en torno al ébola -específicamente, la ausencia de vacunas durante el período más álgido de la crisis $^{-79}$ la disponibilidad de recursos alternativos se ve afectada de forma dramática. Este escenario de carencias extremas complica aun más cualquier evaluación sobre la aceptabilidad de tal o cual medida. Aunque la situación de ningún modo podría justificar una desatención total de los derechos individuales en aras del bienestar de la población, tampoco se considera viable condenar el uso de medidas que en una situación "ordinaria", estarían injustificadas si no se respetan ciertos requerimientos procedimentales básicos. ${ }^{80}$

Dicho esto, cualquier ecuación que se formule para la manera en como se enfrenta una situación extrema como el brote de ébola en África, tiene que incluir una valoración de aquellos derechos ${ }^{81}$ considerados como límites infranqueables, máxime que los instrumentos en esta materia, como el Pacto Internacional de Derechos Civiles y Políticos, como la Carta Africana, prevén la eventualidad de situaciones de emergencia.

Systems Fund" en The Lancet, vol. 384, no. 9951, Londres, Elsevier, 11 de Octubre de 2014, pp. e49-e51.

79 Esta carencia ya se expone en Justo Manuel Menéndez, Fernando Simón y José Barberán, "Enfermedad por virus ébola. Una visión global”... op. cit., p. 235.

80 Dichos requerimientos se retoman de algunos principios constitucionales básicos, y se estima que, por ejemplo, en el ámbito jurídico mexicano, este tipo de actos tendrían que estar regidos por el principio de legalidad establecido en el artículo 16 constitucional, en la medida en que la cuarentena y el aislamiento se caracterizan por tener un carácter provisional. Véase la Jurisprudencia P./J.40/96, del Pleno de la Suprema Corte de Justicia de la Nación, visible en el Semanario Fudicial de la Federación y su Gaceta, Tomo IV, Novena Época, Julio de 1996, p. 5, con el rubro "ACTOS PRIVATIVOS Y ACTOS DE MOLESTIA. ORIGEN Y EFECTOS DE LA DISTINGIÓN".

81 Esta afirmación parte de una visión diferenciada de los derechos, que es respaldada por el hecho de que no todos pueden ser motivo de limitación o restricción en casos de emergencia. Para un punto de vista teórico - e incluso crítico- de esta naturaleza de los derechos, así como una explicación más amplia de las ocasiones en que los derechos "chocan” entre sí, Martti Koskenniemi, op. cit., pp. 142-147. 
Ahora bien, la evaluación sobre si hubo un uso excesivo de facultades al implementar medidas agresivas frente a un brote epidémico puede realizarse ya sea en un plano "general", en el que su utilización no puede justificarse bajo ningún argumento dada la naturaleza misma de la enfermedad, ${ }^{82}$ o en un plano "individual" de caso por caso, en el que se tendría que evaluar si la cuarentena o el aislamiento se realizó después de llevar a cabo un análisis de la situación que amerite su aplicación.

Empero, se considera que este análisis simplemente no se encuentra disponible en el caso del cordón sanitario - conocido también como "cuarentena comunitaria"-83 pues el grave problema que surge con la aplicación de estas medidas generales e indiscriminadas, es que resulta prácticamente imposible llevar a cabo un tipo de evaluación de caso por caso, ${ }^{84}$ toda vez que se aplica a un grupo o colectividad de personas de forma simultánea. De ahí, que la justificación de adoptar estas medidas opera casi exclusivamente en términos del derecho de una colectividad a la protección, que se impone sobre derechos humanos individuales, específicamente el de libre tránsito.

Todo ello ilustra la tensión inevitable entre unos y otros derechos, que si bien encuadran dentro del catálogo de aquellos que pueden

82 De nuevo, esta afirmación sería aplicable para el caso de la pandemia por influenza $\mathrm{A}(\mathrm{H} 1 \mathrm{~N} 1)$. Se ha señalado que aquellos países que utilizaron estas medidas incurrieron en un exceso, si bien las medidas más agresivas fueron implementadas en muy pocos casos, según se expone en Bradly Condon y Tapen Sinha, "The effectiveness of pandemic preparations...", op. cit., pp. 15-17.

83 Para más información sobre un caso de la aplicación de esta medida en una aldea de Liberia, véase Tolbert Nyenswayh y otros, "Community Quarantine to Interrupt Ebola Transmission-Mawah Village, Bong County, Liberia, August-October 2014" en Morbidity and Mortality Weekly Report, vol. 64, no. 7, Centers for Disease Control and Prevention, Febrero 27 de 2015, pp. 179-182, disponible en <http://stacks.cdc.gov/ view/cdc/29283>, [última consulta, 20 de septiembre de 2015].

84 Cabe señalar que dada la falta de aplicación de esta medida durante largo tiempo, hay una notable escasez de literatura científica respecto de su modo de empleo y efectividad médica frente a una enfermedad como el ébola. 
ser limitados o restringidos, requieren no sólo de una adecuación técnica, como fue señalado en líneas precedentes, sino también de una apreciación del contexto específico en el que ocurre una emergencia. Las distintas circunstancias adversas que fueron enumeradas a lo largo del artículo, indican que nos encontramos ante un escenario muy lejos del óptimo, por lo que ciertos dilemas incluso llegan a ser inexistentes. ${ }^{85}$

Dicho esto, de nueva cuenta hay que subrayar el impacto que tienen las recomendaciones de la OMS en la observancia de los derechos humanos frente a una crisis como el ébola. La autorización o no de tomar ciertas medidas en sus recomendaciones puede considerarse como una restricción en sí misma, en tanto se estima que los Estados se apoyan en ellas para ejecutar acciones en materia de salud pública. ${ }^{86}$

Ante lo delicado de una restricción de derechos, y toda vez que no es posible aplicar los mismos criterios jurídicos a los actos no vinculantes de la OMS - aun cuando las recomendaciones temporales en comento tienen ciertos requisitos legales ${ }^{-87}$ lo menos que

85 De nuevo, la ausencia de una vacuna no permite que se "ponderen" los costos de su uso frente al de las cuarentenas, lo que es planteado en Daniel Markovits, "Quarantines and Distributive Justice", en The Fournal of Law, Medicine \& Ethics, vol. 33, no. 2, Nueva York, American Society of Law, Medicine \& Ethics, Junio de 2005, p. 324.

86 Actualmente, hay un debate doctrinal persistente en torno a la dificultad de establecer un vínculo de causa-efecto entre lo dispuesto por instrumentos no vinculantes en el plano internacional y las medidas adoptadas por autoridades nacionales, tal como se desarrolla en Matthias Goldmann, "We Need to Cut Off the Head of the King: Past, Present and Future Approaches to International Soft Law" en Leiden Fournal of International Law, vol. 25, no. 2, Cambridge, Cambridge University Press, Junio de 2012, p. 353.

87 Se ha sostenido que, de no seguir el procedimiento establecido en el Reglamento Sanitario Internacional para la emisión de una Declaración de Emergencia de Salud Pública de Importancia Internacional, la OMS podría incurrir en responsabilidad internacional, en Gian Luca Burci y Clemens Feinäugle, "The ILC's articles seen from a WHO perspective", op. cit., p. 187. Un argumento similar, aunque 
podría esperarse es que estos actos gocen, cuando menos, de una legitimidad en aras de justificar su uso. ${ }^{88}$

\section{vil. Conclusiones}

Aunque el problema que se ha abordado en estas líneas pareciera ser exclusivo al contexto de África occidental, es imperioso tomar en serio la postura del Comisionado Especial sobre ébola de las Naciones Unidas, en el sentido de que esta enfermedad "no se habrá esfumado de ningún país, hasta que se haya esfumado de todos los países". ${ }^{89}$

La preocupación ante fenómenos como el ébola ha conducido, y seguirá conduciendo a un desarrollo de la cooperación internacional en estos temas, en tanto se entiende que es un problema de índole global que requiere también de respuestas globales. ${ }^{90}$ Si bien es menester concientizar respecto de la gravedad del asunto, no menos cierto es que nunca es recomendable ceder frente al pánico

con ciertos matices, podría formularse en el caso de las recomendaciones temporales, conforme al contenido del artículo 17 del Reglamento Sanitario Internacional.

88 Rüdiger Wolfrum, "Legitimacy of International Law from a Legal Perspective: Some Introductory Considerations" en Rüdiger Wolfrum y Volker Röben (eds.), Legitimacy in International Law, Heidelberg, Springer/Max-PlanckInstitut für ausländisches öffentliches Recht und Völkerrecht, 2008, p. 6.

89 Véase el discurso pronunciado el 25 de enero de 2015 ante la 136a. Sesión Especial de la Junta Ejecutiva de la Organización Mundial de la Salud, disponible en: <http://www.who.int/mediacentre/events/2015/eb136/speech-david-nabarro/ en/\#>, [última consulta, 20 de septiembre de 2015]..

90 De ahí que las preocupaciones suscitadas por las enfermedades contagiosas contribuyen a que algunos cataloguen a la salud como un "bien público global". Véase Lincoln G. Chen, Tim Evans y Richard A. Cash, "Health as a Global Public Good" en Inge Kaul y otros (eds.), Global public goods: International Cooperation in the $21^{\text {st }}$ century, Programa de las Naciones Unidas para el Desarrollo/Oxford University Press, Estados Unidos, 1999, p. 284. 
en la toma de decisiones, ${ }^{91}$ so riesgo de incurrir en una restricción excesiva de los derechos indivuales.

Es factible suponer, sin ínfulas de clarividencia, que la reciente emergencia ocasionada por el brote de ébola no será la última vez en que las libertades individuales colisionen con el ámbito de la salud pública. ${ }^{92}$ De cara al escenario cada vez más complejo y abarrotado de la salud internacional, en el que la principal autoridad en temas de salud, la OMS, ha tenido y tendrá que interactuar con otros actores, ${ }^{93}$ los instrumentos continuarán creciendo en número y también en complejidad.

A pesar de que no hay por el momento una solución conceptual definitiva, por lo menos el discutir la relevancia del problema contribuye a un entendimiento, desde la gobernanza global, de que la distinción vinculante/no vinculante, obligatorio/no obligatorio, no basta por sí misma para dar cuenta de cuáles son los actos que deben interesarnos en los estudios jurídicos. No vaya a ser que no nos demos cuenta de cuándo los efectos que constriñen o limitan a los Estados y a los individuos ingresaron "por la puerta de atrás".

91 Drazen, Jeffrey M. y otros, "Ebola and Quarantine" en The New England Fournal of Medicine, Vol. 371, No. 21, Massachusetts Medical Society, Estados Unidos, 20 de Noviembre de 2014, p. 2030.

92 Sarathi Kalra y otros, "The Emergence of Ebola as a Global Health Security Threat: From "Lessons Learned" to Coordinated Multilateral Containment Efforts", op. cit., p. 171.

93 Se enfatiza la necesidad de una coordinación entre la OMS y otras instituciones como el Banco Mundial, o países como los que conforman el G7, en Bill Gates, op. cit., p. 1384. 